\title{
Innate Immunity in Lobsters: Partial Purification and Characterization of a Panulirus cygnus Anti-A Lectin
}

\author{
Robert L. P. Flower \\ Australian Red Cross Blood Service, Queensland University of Technology, Kelvin Grove, QLD 4059, Australia \\ Correspondence should be addressed to Robert L. P. Flower, rflower@redcrossblood.org.au
}

Received 27 September 2011; Accepted 17 October 2011

Academic Editors: L. Bordin and B. Wachowicz

Copyright () 2012 Robert L. P. Flower. This is an open access article distributed under the Creative Commons Attribution License, which permits unrestricted use, distribution, and reproduction in any medium, provided the original work is properly cited.

\begin{abstract}
A lectin detected in haemolymph from the Australian spiny lobster Panulirus cygnus agglutinated human ABO Group A cells to a higher titre than Group O or B. The lectin also agglutinated rat and sheep erythrocytes, with reactivity with rat erythrocytes strongly enhanced by treatment with the proteolytic enzyme papain, an observation consistent with reactivity via a glycolipid. The lectin, purified by affinity chromatography on fixed rat-erythrocyte stroma, was inhibited equally by $N$-acetylglucosamine and $N$-acetylgalactosamine. Comparison of data from gel filtration of haemolymph (behaving as a 1,800,000 Da macromolecule), and polyacrylamide gel electrophoresis of purified lectin (a single 67,000 Da band), suggested that in haemolymph the lecin was a multimer. The purified anti-A lectin autoprecipitated unless the storage solution contained chaotropic inhibitors ( $125 \mathrm{mmol} / \mathrm{L}$ sucrose: $500 \mathrm{mmol} / \mathrm{L}$ urea). The properties of this anti-A lectin and other similar lectins are consistent with a role in innate immunity in these invertebrates.
\end{abstract}

\section{Introduction}

Lectins are carbohydrate-reactive ligands that occur commonly in nature $[1,2]$. These are proteins and glycoproteins with carbohydrate-specific ligand activity that are heat sensitive and dependant on divalent cations [2]. Lectins react with sugars in glycolipids, glycoproteins or oligosaccharides [1-3], and agglutinate erythrocytes via cell surface glycoproteins and glycolipids $[1,2]$. Agglutination by lectins in vitro can be specifically inhibited with complementary simple sugars or oligosaccharides $[1,2]$.

Lectin haemagglutinins have been described in various species in the family Panuliridae (lobsters). A haemagglutinin from the freshwater lobster Pacifastacus leniusculus had high specific activity against trypsinized rabbit erythrocytes and was inhibited by sialoglycoproteins such as mucin, fetuin, and ovalbumin [4-6]. A haemagglutinin of unknown specificity has been reported for haemolymph from Panulirus interruptus [7]. Although glycolipids appear to be at low levels on the surface of rat erythrocytes, there is enhaced exposure of glycolipids after treatment with proteolytic enzymes [8]. Agglutination activity for many of these lectins is enhanced by proteolytic enzyme treatment, providing evidence that these lectins react preferentially with glycolipids rather than glycoproteins.

There is also an example of a plant lectin that reacts more strongly with proteolytic enzyme-treated rat red cells; the Solanum tuberosum (potato) lectin. This lectin that reacts preferentially with rat erythrocytes is most efficiently inhibited by a small oligosaccharide, $N N^{\prime} N^{\prime \prime} N^{\prime \prime \prime}$-tetra- $N$-acetylchitotetraose [9]. This lectin is also a strong agglutinin for rat erythrocytes that have been treated with proteolytic enzymes $[1,9]$.

When a suitable substrate is available, purification strategies based on affinity chromatography provide a convenient single-step purification. There have been a number of reports of isolation of invertebrate lectins by affinity chromatography with fixed erythrocytes as a substrate. Reitherman [10] reported purification using formalinised erythrocytes as a general affinity adsorbent. Ochoa and Kristiansen [11] reported a similar procedure, using of red cell stroma as an affinity adsorbent. More specific techniques have included the use Sepharose-colominic acid affinity chromatography to purify a sialic acid-specific lectin (LAg1) [12]. 
This report describes the characterisation of a lectin from Panulirus cygnus with selective reactivity with human ABO group A red cells and with rat red cells. The properties and sugar reactivity of lectin are similar to characterised antibacterial lectins and it hypothesised that in this animal, this lectin may contribute to antibacterial activity in the haemolymph.

\section{Materials and Methods}

2.1. Haemolymph. Lobsters of the species Panulirus cygnus (George, 1962) were trapped in waters near Perth, Western Australia. Within 12 hours of capture, an 18-gauge needle was inserted into the haemocoel, and haemolymph withdrawn into a $50 \mathrm{~mL}$ syringe. The haemolymph was allowed to clot, the exudate collected and stored in $1 \mathrm{~mL}$ portions at $-20^{\circ} \mathrm{C}$.

2.2. Haemagglutination (HA) Tests. Human type A, B, and O erythrocytes collected into EDTA were obtained from the Australian Red Cross Blood Transfusion Service. Erythrocytes from chicken, dog, cat, horse, sheep, rat, and guinea pig collected in EDTA by venipuncture or cardiac puncture of clinically normal animals were obtained from a Diagnostic Veterinary Laboratory. Erythrocytes were washed and made up as $2.5 \%(\mathrm{v} / \mathrm{v})$ suspensions in $100 \mathrm{mmol} / \mathrm{L}$ phosphate-buf-

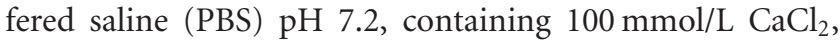
$20 \mathrm{mmol} / \mathrm{L} \mathrm{MgCl}_{2}$ and $15 \mathrm{mmol} / \mathrm{L}$ bovine serum albumin. Papain was obtained from CSL (Parkville, Victoria, Australia) and erythrocytes treated using standard procedures recommended by the manufacturer. Briefly, erythrocytes were washed 3 times in PBS and $500 \mu \mathrm{L}$ of packed erythrocytes incubated for $15 \mathrm{~min}$ at $37^{\circ} \mathrm{C}$ with $500 \mu \mathrm{L}$ of a $1 \%(\mathrm{w} / \mathrm{v})$ papain solution in $200 \mathrm{mmol} / \mathrm{L}$ acetate buffer $\mathrm{pH}$ 5.8. At the end of the incubation period, the papainised erythrocytes were diluted in $100 \mathrm{~mL}$ of PBS and used immediately for HA tests.

HA tests were carried out in plastic 96-well V-bottom microtitre trays. Serial $1: 2$ dilutions of lectin were made in $25 \mu \mathrm{L}$ of PBS and $25 \mu \mathrm{L}$ of a $0.5 \%$ erythrocyte suspension added to each dilution. After 30-minute incubation at room temperature $\left(20-25^{\circ} \mathrm{C}\right)$, haemagglutination was observed and scored on a $1+$ to $4+$ scale: a $1+$ reaction was scored when erythrocytes were in small clumps but all of the erythrocytes were involved. The titre was interpreted as the highest dilution which produced at least $1+$ agglutination of the $25 \mu \mathrm{L}$ volume used in the test. Titrations were performed in triplicate and repeated at least twice.

2.3. Inhibition of Haemagglutination by Sugars. Arbutin, cellobiose, $N$-acetylgalactosamine, $\beta$-methylgalactoside, $N$-acetylglucosamine, glucose, a-methylglucoside, lactose, maltose, mannose, $\alpha$-methyl-mannoside, melibiose, raffinose and sucrose, all in the D-configuration, and L-Fucose were purchased from the Sigma Chemical Company (St. Louis, USA) were made up as $100 \mathrm{mmol} / \mathrm{L}$ solutions in PBS. Inhibition of HA by sugars was determined in V-bottom 96-well plastic microtitre trays, by mixing $25 \mu \mathrm{L}$ of $1: 2$ serial dilutions of sugar with 5 rat erythrocyte-HA units of haemolymph or affinity-chromatography purified lectin in $25 \mu \mathrm{L}$ of PBS. After incubation at room temperature for 30 mins, $25 \mu \mathrm{L}$ of a $0.5 \%$ suspension of rat erythrocytes was added. The results reported were a mean of 3 determinations, for the concentration of the sugar at which complete inhibition of HA was observed.

2.4. Preparation of an Affinity Column and Affinity Chromatography. An affinity column of glutaraldehyde-fixed rat erythrocyte membrane proteins was prepared. Blood from 4 rats was pooled, washed, and made up as $5 \%$ suspension. Five $\mathrm{mL}$ of this suspension were added to $3 \mathrm{~mL}$ of Con A-Sepharose (Pharmacia Fine Chemicals, Uppsala, Sweden) and incubated for 2 hours at $4^{\circ} \mathrm{C}$ on a rotating mixer. Unbound erythrocytes were removed by washing three times with PBS. For PBS washes, $20 \mathrm{~mL}$ of PBS were added to the suspension, which was centrifuged at $100 \mathrm{~g}$ for $5 \mathrm{~min}$ and the supernatant discarded.

To lyse erythrocytes bound to the Con A, $5 \mathrm{~mL}$ of a $1 \%$ solution of Triton-X 100 (BDH Chemicals, Poole, UK) were added to the pellet and the suspension was shaken for $1 \mathrm{~min}$. The Triton-X was then removed by washing 5 times with $20 \mathrm{~mL}$ of PBS as described above.

The rat erythrocyte membrane proteins were fixed to the Con A-Sepharose and the unreacted Con A inactivated by incubation at room temperature for $15 \mathrm{~min}$ with $10 \mathrm{~mL}$ of $10 \%$ glutaraldehyde. The glutaraldehyde was then removed by washing 3 times with $20 \mathrm{~mL}$ of PBS as described above. This rat erythrocyte membrane- (REM-) Sepharose immunosorbent was used to purify the Panulirus cygnus lectin by affinity chromatography. Two $\mathrm{mL}$ of the REM-Sepharose were poured into a C 10/10 chromatography column (Pharmacia Fine Chemicals, Uppsala, Sweden) and washed with $100 \mathrm{~mL}$ of PBS. For affinity chromatography $1 \mathrm{~mL}$ of Panulirus cygnus haemolymph was passed through the column and the column then washed with $100 \mathrm{~mL}$ of PBS.

In separate experiments, elution of lectin was attempted

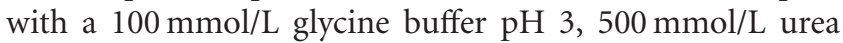
$125 \mathrm{mmol} / \mathrm{L}$ sucrose in PBS or $200 \mathrm{mmol} / \mathrm{L}$ solutions of the sugars, $\mathrm{N}$-acetylglucosamine, b-methylglucoside, maltose, $\mathrm{N}$-acetylgalactosamine, lactose, a-methylgalactoside or mannose, in PBS. Sugars were obtained from the Sigma Chemical Company (St. Louis, Missouri, USA). One mL of each solution was applied to the column, incubated for $10 \mathrm{~min}$ at room temperature, the column was then eluted with $5 \mathrm{~mL}$ of the same solution at a flow rate of $10 \mathrm{~mL}$ per hour and $1 \mathrm{~mL}$ fractions collected.

The quantity of protein in the eluates was determined by measurement of the $A_{280}$. The eluted samples were dialysed overnight against $500 \mathrm{mmol} / \mathrm{L}$ urea: $125 \mathrm{mmol} / \mathrm{L}$ sucrose. Portions of the dialysed fractions were diluted $1: 10$ for HA tests with rat erythrocytes, to dilute the urea-sucrose solution. Recovery was determined by dividing the total HA activity applied to the column by the total HA recovered.

Fractions containing HA activity were pooled and stored at $4^{\circ} \mathrm{C}$ in $125 \mathrm{mmol} / \mathrm{L}$ sucrose $-500 \mathrm{mmol} / \mathrm{L}$ urea or frozen at $-70^{\circ} \mathrm{C}$ and used as a source of purified lectin described in other experiments. 
TABLE 1: Haemagglutination of normal and papain-treated erythrocytes by P. cygnus haemolymph and affinity chromatography purified lectin.

\begin{tabular}{|c|c|c|c|c|}
\hline \multirow[b]{3}{*}{ Type of erythrocyte } & \multicolumn{4}{|c|}{ HA titre ${ }^{a}$} \\
\hline & \multicolumn{2}{|c|}{ Untreated erythrocytes } & \multicolumn{2}{|c|}{ Papain-treated erythrocytes } \\
\hline & Haemolymph & Purified lectin ${ }^{\mathrm{b}}$ & Haemolymph & Purified lectin ${ }^{b}$ \\
\hline Human 0 & 16 & 20 & 16 & 20 \\
\hline Human A & 32 & 40 & 64 & 80 \\
\hline Human B & 16 & 20 & 16 & 20 \\
\hline Chicken & 0 & 0 & 16 & 20 \\
\hline Rat & 4,096 & 5,120 & 128,000 & 128,000 \\
\hline Sheep & 16 & 20 & 64 & 80 \\
\hline
\end{tabular}

${ }^{a}$ Titres were determined as described in the text.

${ }^{b}$ Lectin was purified by affinity chromatography on REM-Sepharose, with sucrose-urea as eluant. The eluate was diluted $1: 10$ and then titrated. The $\mathrm{A}_{280}$ of the undiluted lectin preparation was 0.2 .

2.5. Contribution of the Lectin to Total Haemolymph Protein: Sepharose 4B Gel Filtration and Agarose Gel Electrophoresis. A Sepharose 4B (Pharmacia-LKB Biotechnology, North Ryde, NSW, Australia) column $50 \mathrm{~cm}$ in length and $2.5 \mathrm{~cm}$ in diameter with a flow rate of $8 \mathrm{~mL} /$ hour was used for gel filtration. One $\mathrm{mL}$ of fresh haemolymph was applied to the column and eluted with a buffer containing $100 \mathrm{mmol} / \mathrm{L}$ Tris/ $\mathrm{HC1} \mathrm{pH}$ 8. Fractions of $5 \mathrm{~mL}$ were collected, the HA titre with rat erythrocytes and $\mathrm{A}_{280}$ measured, and then equal volumes of $500 \mathrm{mmol} / \mathrm{L}$ urea: $125 \mathrm{mmol} / \mathrm{L}$ sucrose added to each fraction. The elution volume for molecular weight markers (feline panleukopenia virus to determine the void volume; human IgM, 960 kilodaltons; human IgG, 150 kilodaltons; and human serum albumin, 69 kilodaltons) had been determined previously. Molecular size was determined from a graph of $V_{e}$ versus $\log _{10}$ molecular size. Agarose gel electrophoresis of haemolymph was carried out on a Gelman (Ann Arbor, Michigan, USA) immunoelectrophoresis apparatus with gels prepared on glass slides $5 \times 8 \mathrm{~cm}$ using $1 \%$ agar in $100 \mathrm{mmol} / \mathrm{L}$ barbiturate buffer, $\mathrm{pH} 8$, with a gel thickness $1.5 \mathrm{~mm}$. A row of wells $1.5 \mathrm{~mm}$ in diameter and $2 \mathrm{~mm}$ apart were punched in the gel $1.5 \mathrm{~cm}$ from the edge of the gel and the wells filled with haemolymph. Gels were electrophoresed at 30 milliamps for 1.5 hours using an LKB (Pharmacia-LKB Biotechnology, North Ryde, NSW, Australia) immunoelectrophoresis apparatus. At the completion of the run, the gels were cut into eight $1 \mathrm{~cm}$ slices and the slices ground in $1 \mathrm{~mL}$ of PBS with a mortar and pestle, centrifuged at $1000 \times g$ for $5 \mathrm{~min}$, and the $\mathrm{A}_{280}$ and HA titre of the supernatant determined.

2.6. Polyacrylamide Gel Electrophoresis (PAGE). Haemoly$\mathrm{mph}$ and purified lectin were electrophoresed on native and reducing polyacrylamide gels on a Bio-Rad (Bio-Rad Laboratories, Sydney, NSW, Australia) system using techniques recommended by the manufacturer. Gels were stained with Coomassie blue and the intensity of bands quantified by scanning with an LKB laser densitometer (Pharmacia-LKB Biotechnology, North Ryde, NSW, Australia).

2.7. Heat Stability and Requirement for Divalent Cations. The HA titre for fresh haemolymph and purified lectin were determined after heating at $37^{\circ} \mathrm{C}$ or at $56^{\circ} \mathrm{C}$ for $30 \mathrm{~min}$. Tests were carried out in plastic 96-well V-bottom microtitre trays. Serial 1:2 dilutions of haemolymph or purified lectin were made in $25 \mathrm{~mL}$ of both PBS with $1 \mathrm{mmol} / \mathrm{L}$ ethylenediaminetetraacetic acid (EDTA) without divalent cations and PBS containing $100 \mathrm{mmol} / \mathrm{L} \mathrm{CaCl}_{2}, 20 \mathrm{mmol} / \mathrm{L} \mathrm{MgCl}_{2}$, and $15 \mathrm{mmol} / \mathrm{L}$ bovine serum albumin. An equal volume $(25 \mathrm{~mL})$ of a $0.5 \%$ suspension of rat erythrocytes, prepared in PBS without divalent cations, was added to each well. After incubation at room temperature for $30 \mathrm{~min}$, HA titres were determined as previously described.

2.8. Autoprecipitation. Five $\mathrm{mL}$ of affinity column purified lectin in PBS with $\mathrm{Ca}^{2+}$ and $\mathrm{Mg}^{2+}$ ions were stored at $4^{\circ} \mathrm{C}$ for 5 days, and $1 \mathrm{~mL}$ of the same preparation was stored in PBS with $125 \mathrm{mmol} / \mathrm{L}$ sucrose: $500 \mathrm{mmol} / \mathrm{L}$ urea for 5 days at $4^{\circ} \mathrm{C}$. The stored lectins were then centrifuged $(2,000 \times g, 15 \mathrm{~min})$ and the precipitate that was recovered dissolved in $200 \mathrm{~mL}$ of a $500 \mathrm{mmol} / \mathrm{L}$ sucrose: $2 \mathrm{~mol} / \mathrm{L}$ urea solution. A $25 \mathrm{~mL}$ sample of the redissolved precipitate was diluted 1:100 in PBS and the HA activity with rat erythrocytes determined.

\section{Results}

Haemolymph from Australian lobster P. cygnus. agglutinated rat erythrocytes to a titre 128 times greater than that for sheep or human erythrocytes (Table 1). After treatment with papain, the titre with rat erythrocytes increased 32 folds (Table 1). Chicken erythrocytes when untreated did not react but were agglutinated by $P$. cygnus lectin after papain treatment (Table 1). There was no significant change in the titres after papain treatment for sheep erythrocytes or human erythrocytes (Table 1). It has been noted in studies of the rat erythrocyte-reactive Solanum tuberosum (potato) lectin rat erythrocytes that there is little $\mathrm{N}$-acetylgalactosamine associated with surface glycoproteins on rat red cells (12) and the lectin most likely reacts through $N$-acetylglucosamine in a $\beta$-linkage displayed on a glycolipid.

The lectin was adsorbed to fixed rat red cells bound to a Sepharose support maxtrix. Elution with various sugars and chaotropic agents was investigated. Lectin was eluted by $\mathrm{N}$-acetylgalactosamine with a $60 \%$ recovery, $\mathrm{N}$-acetylglucosamine with a $115 \%$ recovery, glycine buffer $\mathrm{pH} 3$ with 
a $115 \%$ recovery, and $125 \mathrm{mmol} / \mathrm{L}$ sucrose: $500 \mathrm{mmol} / \mathrm{L}$ urea with $115 \%$ recovery (Table 2). No lectin detectable by HA with rat erythrocytes was eluted from the REM-Sepharose column by $0.1 \mathrm{~mol} / \mathrm{L}$ solutions of maltose, $\alpha$-methylgalactoside, lactose, or mannose. A single protein of 67 kilodaltons molecular size was detected by PAGE of affinity-purified lectin.

When purified lectin was stored in PBS at $4^{\circ} \mathrm{C}$ for 5 days, a white precipitate developed and complete loss of HA activity was observed. When the white precipitate was recovered by centrifugation $(2,000 \times g, 15 \mathrm{~min})$ and redissolved in $200 \mathrm{~mL}$ of a $500 \mathrm{mmol} / \mathrm{L}$ sucrose: $2 \mathrm{~mol} / \mathrm{L}$ urea solution, only $10 \%$ of the original HA activity with rat erythrocytes was recovered. The purified lectin was stabilised by storage in $125 \mathrm{mmol} / \mathrm{L}$ sucrose: $500 \mathrm{mmol} / \mathrm{L}$ urea, and after storage at $4^{\circ} \mathrm{C}$ for 5 days there was no loss of activity.

The HA activity of purified lectin with rat erythrocytes was inhibited by $6.2 \mathrm{mmol} / \mathrm{L} N$-acetylglucosamine, $12.5 \mathrm{mmol} / \mathrm{L} N$-acetylgalactosamine, and $50 \mathrm{mmol} / \mathrm{L} \beta$ methylgalactoside but was not inhibited by $100 \mathrm{mmol} / \mathrm{L}$ solutions of mannose, arbutin, cellobiose, fucose, lactose, maltose, melibiose, raffinose, or sucrose (Table 3). The profile of sugars that inhibited HA activity of haemolymph and affinity-purified lectin by sugars was identical (Table 3 ).

Lectin activity was detected when PBS with $\mathrm{Ca}^{2+}$ and $\mathrm{Mg}^{2+}$ ions was used as a diluent, no activity was detected in PBS containing $1 \mathrm{mmol} / \mathrm{L}$ EDTA. When purified lectin was heated at $56^{\circ} \mathrm{C}$ for $30 \mathrm{~min}$, no HA activity with rat erythrocytes remained. When haemolymph was subject to agarose electrophoresis, the major haemolymph proteins migrated in a region of $\alpha$-electrophoretic mobility while the lectin, representing $5.8 \%$ of the total protein, was detected in a region of $\beta$ electrophoretic mobility. When haemolymph was subjected to gel filtration on Sepharose 4B, the HA activity eluted as a single peak that comprised $4 \%$ of the total protein, with an estimated molecular size of 1.8 megadaltons. This activity was well separated from a peak in the elution profile that represented $96 \%$ of the total protein, composed of proteins ranging between 100 and 300 kilodaltons molecular size. This was in contrast to that single $67,000 \mathrm{Da}$ band that was detected by laser densitometer scanning of polyacrylamide gels following electrophoresis of affinity-purified lectin, suggesting that in haemolymph the lectin existed as a multimeric macromolecule.

\section{Discussion}

For the $P$ cyguns anti-A lectin characterised in this study, a $67,000 \mathrm{Da}$ subunit was detected under reducing conditons, with $1,800,000 \mathrm{Da}$ multimer observed by gel filtration. The purified lectin also autoprecipitated in $\mathrm{PBS}$ at $4^{\circ} \mathrm{C}$, suggesting that there was spontaneous aggregation unless it was stored under chatropic conditions; in this study with sucrose-urea. The haemagglutinating lectin in P. cygnus haemolymph was heat sensitive and required divalent cations for activity, properties commonly observed for invertebrate lectins [2].
TABLE 2: Elution of P. cygnus lectin from REM-Sepharose.

\begin{tabular}{lcc}
\hline Eluant & HA titre & $\mathrm{A}_{280}$ \\
\hline $\begin{array}{l}N \text {-acetylgalactosamine } \\
(100 \mathrm{mmol} / \mathrm{L})\end{array}$ & 1024 & 0.18 \\
$\begin{array}{l}\mathrm{N} \text {-acetylglucosamine } \\
(100 \mathrm{mmol} / \mathrm{L})\end{array}$ & 5120 & 0.20 \\
$\begin{array}{l}\text { Glycine buffer } \mathrm{pH} 3 \\
(100 \mathrm{mmol} / \mathrm{L})\end{array}$ & 5120 & 0.21 \\
$\begin{array}{l}\text { Sucrose }(125 \mathrm{mmol} / \mathrm{L}) \text {-urea } \\
(500 \mathrm{mmol} / \mathrm{L})\end{array}$ & 5120 & 0.20 \\
\hline
\end{tabular}

${ }^{a}$ The HA titre with rat erythrocytes was determined for protein-containing fractions as described in the text.

TABLe 3: Inhibition of haemagglutination by P. cygnus lectin with sugars. Minimum inhibitory concentration $(\mathrm{mmol} / \mathrm{L})^{\mathrm{a}}$.

\begin{tabular}{lcc}
\hline Sugar & Haemolymph & Purified lectin $^{\mathrm{b}}$ \\
\hline$N$-acetylgalactosamine & 12.5 & 12.5 \\
$N$-acetylglucosamine & 12.5 & 6.2 \\
$\beta$-methylgalactoside & 50 & 50 \\
\hline
\end{tabular}

${ }^{a}$ The minimum inhibitory concentration is the lowest concentration of sugar that completely inhibited HA with rat erythrocytes for haemolymph or purified lectin diluted to contain 5 rat erythrocyte-HA units in $25 \mathrm{~mL}$.

${ }^{b}$ Purified lectin was obtained by affinity chromatography on REMSepharose, with sucrose-urea as eluant. The lectin was diluted $1: 100$ to give 5 HA units for inhibition tests. The $\mathrm{A}_{280}$ of the undiluted lectin preparation was 0.2 .

The properties of the P. cygnus anti-A lectin were similar to those of the hemagglutinin from Pacifastacus leniusculus. Both lectins have been found to have a high specific activity against erythrocytes treated with proteolytic enzymes. The purified Pacifastacus leniusculus hemagglutinin was 420,000 Da., which dissociated to monomeric glycoprotein subunits [4-6]. In a second report, an $\mathrm{N}$-acetylgalactosamine reactive $11 \mathrm{~S}$ macromolecular lectin from Homarus americanus (LAg-2) was reported to have properties similar to the P. cygnus lectin in that it dissociated subunits of $55,000 \mathrm{Da}$ $[13,14]$.

The procedure for preparation of an affinity substrate, with gluteraldehyde as a fixative, was similar to those of Desai and Allen [9] who reported the use of formalinised erythrocytes and Reitherman et al. [10] who reported the use of erythrocyte stroma. It may be possible to identify a more specific substrate using techniques similar to those reported for the LAg1 sialic acid-specific lectin [11] or for the potato lectin as it has a similar activity profile [9].

Detection of lectins that react with $N$-acetyl-substituted sugars is common in invertebrate species. A human A RBC agglutinin from marine prawn Penaeus indicus, with reactivity enhanced by trypsinisation and a specificity for acetylated aminosugars, was inhibited by Salmonella lipopolysaccharide [15]. A lectin from the pearl oyster, Pinctada fucata (Martensii) also has properties similar to the P. cygnus lectin described in this report; a sugar specificity for $\mathrm{N}$-acetylgalactosamine and a subunit structure with subunits of $20,000 \mathrm{Da}$ in aggregates of 440,000 Da in haemolymph [16].

Yeaton [17] listed 40 invertebrate species with lectins with known sugar specificity and 16 of these were reactive 
with acetylated aminosugars such as $\mathrm{N}$-acetyl galactosamine. Antibacterial activity has also been described for $N$-acetyl-Dglucosamine or $\mathrm{N}$-acetyl-D-galactosamine specific lectinstachylectin-2 and tachylectin 3 from the Japanese horseshoe crab, Tachypleus tridentatus [18, 19]. The hemagglutinating activity of tachylectin 3 was strongly inhibited by S-type LPSs from Escherichia coli O111:B4 and other S-type lipopolysaccharides (LPSs) from Gram-negative bacteria but not by $\mathrm{R}$-type LPSs lacking $\mathrm{O}$-antigens. The authors suggest that tachylectin-3 specifically recognizes Gram-negative bacteria through the unique structural units of $\mathrm{O}$-antigens. It is not known how many of these also display antibacterial activity that would be expected from their pattern of sugar specificity.

Antibacterial activity in Panulirus cygnus haemolymph, reported as nonspecific and mainly associated with haemocytes [20], was investigated as an indicator of lobster immune-system status and health condition. Lobsters that survived a simulated live-shipment procedure exhibited significantly lower antibacterial activity in haemolymph than did those found dead or weak after holding in a tank, leading to a conclusion that handling stress was associated with high activity levels in lobster haemolymph [20]. Lectin reactivity with Gram-negative bacteria has been consistently reported for marine invertebrates $[21,22]$. There are many similarities between the P. cygnus anti-A lectin reported here blood group reactive lectins from other invertebrates that play a role in defence against pathogens [23]. A semiquantitative assay of the anti-A lectin levels by haemagglutination is a convenient rapid test that can be used to measure changes in this haemolymph protein in response to environmental conditions and to investigate whether the reported antibacterial activity is mediated by this lectin.

\section{References}

[1] E. R. Gold and P. Balding, Receptor Specific Proteins, Excerpta Medica, Amsterdam, Netherlands, 1st edition, 1975.

[2] N. Sharon, "Lectins: past, present and future," Biochemical Society Transactions, vol. 36, no. 6, pp. 1457-1460, 2008.

[3] N. Stromberg, P.-G. Nyholmt, I. Paschert, and S. Normark, "Saccharide orientation at the cell surface affects glycolipid receptor function," Proceding of the National Academy of Sciences of USA, vol. 88, pp. 9340-9344, 1991.

[4] B. Duvic and K. Soderhall, "Purification and characterization of a $\beta$-1,3-glucan binding protein from plasma of the crayfish Pacifastacus leniusculus," Journal of Biological Chemistry, vol. 265, no. 16, pp. 9327-9332, 1990.

[5] B. Duvic and K. Soderhall, "Purification and partial characterization of a $\beta$-1,3-glucan-binding-protein membrane receptor from blood cells of the crayfish Pacifastacus leniusculus," European Journal of Biochemistry, vol. 207, no. 1, pp. 223-228, 1992.

[6] P. Kopacek, L. Grubhoffer, and K. Soderhall, "Isolation and characterization of a hemagglutinin with affinity for lipopolysaccharides from plasma of the crayfish Pacifastacus leniusculus," Developmental and Comparative Immunology, vol. 17, no. 5, pp. 407-418, 1993.

[7] A. Tyler and B. T. Scheer, "Natural hetero-haemagglutinins in the serum of the spiny lobster Panulirus interruptus," The Bioliological Bullulletin, vol. 89, pp. 193-200, 1945.
[8] C. G. Gahmberg and S. Hakomori, "External labeling of cell surface galactose and galactosamine in glycolipid and glycoprotein of human erythrocytes," Journal of Biological Chemistry, vol. 248, no. 12, pp. 4311-4317, 1973.

[9] N. N. Desai and A. K. Allen, "The purification of potato lectin by affinity chromatography on an $\mathrm{N}, \mathrm{N}^{\prime}, \mathrm{N}^{\prime \prime}$-triacetylchitotriose-Sepharose matrix," Analytical Biochemistry, vol. 93, pp. 88-90, 1979.

[10] R. W. Reitherman, S. D. Rosen, and S. H. Barondes, "Lectin purification using formalinised erythrocytes as a general affinity adsorbant," Nature, vol. 248, no. 5449, pp. 599-600, 1974.

[11] J. L. Ochoa and T. Kristiansen, "Stroma: as an affinity adsorbent for non-inhibitable lectins," FEBS Letters, vol. 90, no. 1, pp. 145-148, 1978.

[12] J. VanderWall, P. A. Campbell, and C. A. Abel, "Isolation of a sialic acid-specific lobster lectin (LAg1) by affinity chromatography on Sepharose-colominic acid beads," Developmental and Comparative Immunology, vol. 5, no. 4, pp. 679-684, 1981.

[13] J. L. Hall and D. T. Rowlands, "Heterogeneity of lobster agglutinins. I. Purification and physiochemical characterization," Biochemistry, vol. 13, no. 4, pp. 821-827, 1974.

[14] J. L. Hall and D. T. Rowlands, "Heterogeneity of lobster agglutinins. II. Specificity of agglutinin-erythrocyte binding," Biochemistry, vol. 13, no. 4, pp. 828-832, 1974.

[15] R. Maheswari, P. Mullainadhan, and M. Arumugam, "Characterisation of a natural haemagglutinin with affinity for acetylated aminosugars in the serum of the marine prawn, Penaeus indicus (H. Milne Edwards)," Fish and Shellfish Immunology, vol. 7, no. 1, pp. 17-28, 1997.

[16] T. Suzuki and K. Mori, "A galactose-specific lectin from the hemolymph of the pearl oyster, Pinctada fucata (Martensii)," Comparative Biochemistry and Physiology B, vol. 92, no. 3, pp. 455-462, 1989.

[17] R. W. Yeaton, "Invertebrate lectins: II diversity of specificity, biological synthesis and function in recognition," Developmental and Comparative Immunology, vol. 5, no. 4, pp. 535$545,1981$.

[18] S. Gokudan, T. Muta, R. Tsuda et al., "Horseshoe crab acetyl group-recognizing lectins involved in innate immunity are structurally related to fibrinogen," Proceedings of the National Academy of Sciences of the United States of America, vol. 96, no. 18, pp. 10086-10091, 1999.

[19] S. I. Kawabata and S. Iwanaga, "Role of lectins in the innate immunity of horseshoe crab," Developmental and Comparative Immunology, vol. 23, no. 4-5, pp. 391-400, 1999.

[20] E. Tsvetnenko, S. Fotedar, and L. Evans, "Antibacterial activity in the haemolymph of western rock lobster, Panulirus cygnus," Marine and Freshwater Research, vol. 52, no. 8, pp. 1407-1412, 2001.

[21] K. Azumi, S. Ozeki, H. Yokosawa, and S. Ishii, "A novel lipopolysaccharide-binding hemagglutinin isolated from hemocytes of the solitary ascidian, Halocynthia roretzi: $\mathrm{t}$ can agglutinate bacteria," Developmental and Comparative Immunology, vol. 15, no. 1-2, pp. 9-16, 1991.

[22] F. J. Cassels, E. W. Odom, and G. R. Vasta, "Hemolymph lectins of the blue crab, Callinectes sapidus, recognize selected serotypes of its pathogen Vibrio parahaemolyticus," Annals of the New York Academy of Sciences, vol. 712, pp. 324-326, 1994.

[23] R. Brown, L. R. Almodovar, H. M. Bhatia, and W. C. Boyd, "Blood group specific agglutinins in invertebrates," Journal of Immunology, vol. 100, no. 1, pp. 214-216, 1968. 


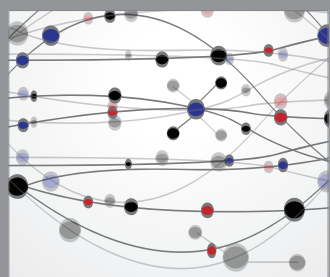

The Scientific World Journal
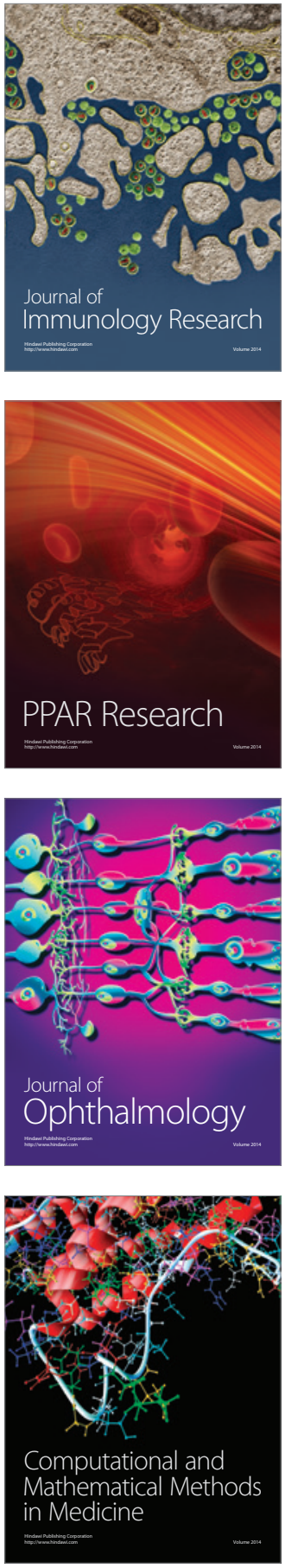

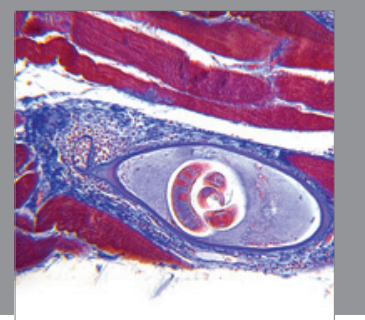

Gastroenterology

Research and Practice
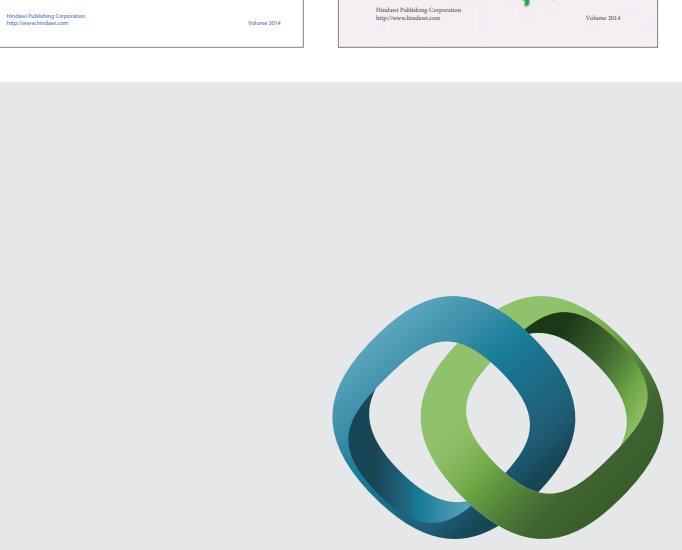

\section{Hindawi}

Submit your manuscripts at

http://www.hindawi.com
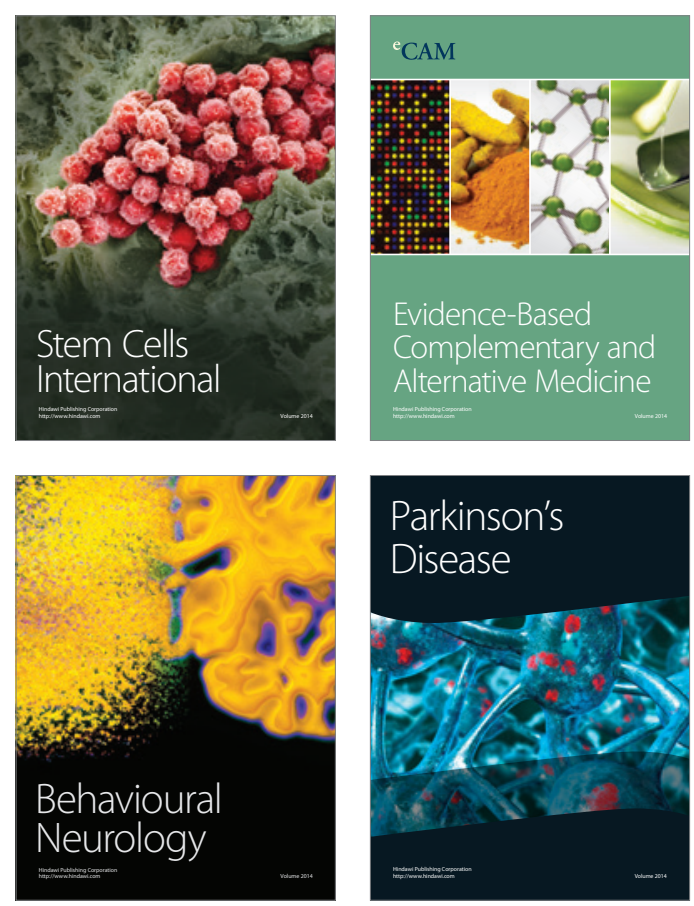

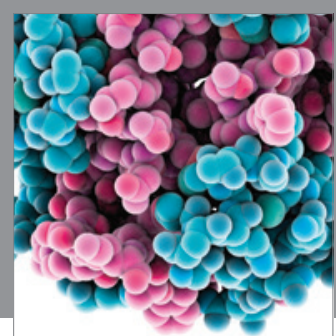

Journal of
Diabetes Research

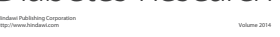

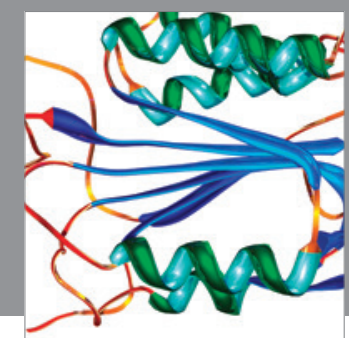

Disease Markers
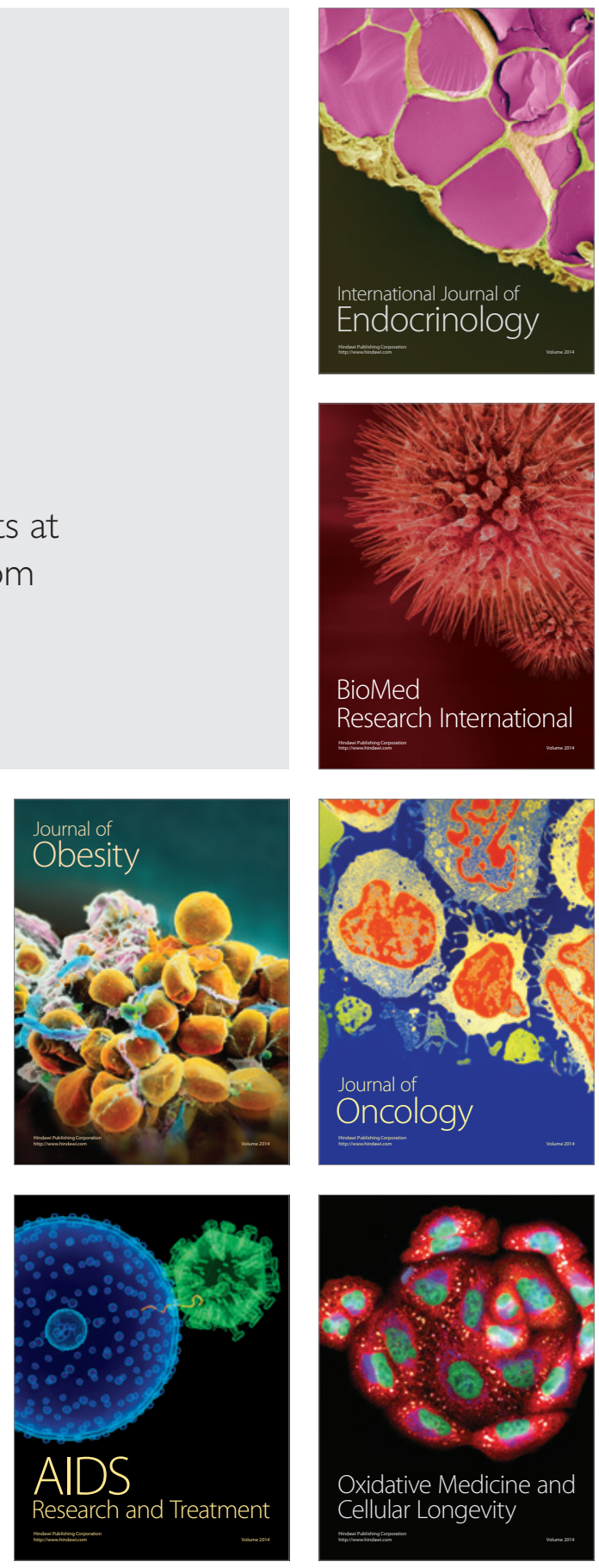